\title{
Importance of Healthy Habits During the COVID-19 Pandemic: Perspective and Suggestions
}

\author{
Marcos Roberto Tovani-Palone ${ }^{1 *}$ (D) Nicola Comini ${ }^{2}$ (D), Andrea Giacalone ${ }^{3}$ (D) Thomas Franchi $^{4}$ (D)
}

\author{
${ }^{1}$ Department of Pathology and Legal Medicine, Ribeirão Preto Medical School, University of São Paulo, Ribeirão Preto, BRAZIL \\ ${ }^{2}$ Università degli Studi di Ferrara, Ferrara, ITALY \\ ${ }^{3}$ Department of Industrial Engineering, Technologies for Sports Medicine and Rehabilitation, University Tor Vergata, Rome, ITALY \\ ${ }^{4}$ The Medical School, The University of Sheffield, Sheffield, UK \\ *Corresponding Author: marcos_palone@hotmail.com
}

Citation: Tovani-Palone MR, Comini N, Giacalone A, Franchi T. Importance of Healthy Habits During the COVID-19 Pandemic: Perspective and Suggestions. Electron J Gen Med. 2022;19(3):em369. https://doi.org/10.29333/ejgm/11874

\begin{tabular}{|c|c|}
\hline ARTICLE INFO & ABSTRACT \\
\hline Received: 1 Aug. 2021 & Numerous preventive measures of social distancing and lockdowns have been imposed by governments and \\
\hline Accepted: 25 Feb. 2022 & $\begin{array}{l}\text { health authorities in order to reduce severe acute respiratory syndrome coronavirus } 2 \text { (SARS-CoV-2) transmission. } \\
\text { This, in turn, has significantly impacted upon physical activity levels and other healthy habits in different countries } \\
\text { around the globe, which may precipitate several negative sequalae on the health of the world population. Here, } \\
\text { we briefly discuss the current scientific evidence on the subject and propose relevant recommendations moving } \\
\text { forwards. }\end{array}$ \\
\hline
\end{tabular}

Keywords: COVID-19, SARS-CoV-2, pandemics, exercise, healthy lifestyle

\section{INTRODUCTION}

In the context of the coronavirus disease 2019 (COVID-19) pandemic, numerous preventative measures including social distancing and the imposition of lockdowns have been enacted by governments and health authorities worldwide, in order to reduce the transmission of severe acute respiratory syndrome coronavirus 2 (SARS-CoV-2). Linked to and as a result of this, recent studies have highlighted the significant impact that these measures have had upon physical activity levels around the globe, which may precipitate several negative sequelae on the health of the world population. These include, amongst others, systemic endocrine and circulatory conditions [1-3], a host of other chronic conditions [1,4], altered sleeping habits [5], and mental health problems [6].

Although the advent of mass vaccination program against COVID-19 are resulting in a reduciton in deaths and hospitalizations in some regions of the world [6], the rapid spread of novel SARS-CoV-2 variants has become responsible for a significant increase in the number of cases in affected countries $[7,8]$. In light of this recurring threat, some factors, such as the variable efficacy of COVID-19 vaccines [9], inequality in their distribution [10], and the occurrence of prolonged symptoms or 'long COVID-19' in a significant percentage of patients [11] are important issues which require consideration.

Therefore, the continued adoption of preventive measures by populations is essential in the ongoing public health efforts to overcome the disease, within which the practice of physical exercise and other healthy habits should play a mainstream role. Physical exercise, a healthy diet, and balanced sleep have been demonstrated to contribute to COVID-19 prevention and the avoidance of life-theatening cases of the disease [4,12]. We briefly discuss the current scientific evidence on the subject and propose relevant recommendations moving forwards.

\section{EXERCISES VERSUS COVID-19 QUARANTINE}

During quarantine and lockdown periods due to COVID-19, the world population has spent more time on electronic communication devices and looking at screens, alongside a reduction in the regular and sustained practice of physical activities. This can result in potentially harmful long-term effects on chronic health conditions [4] including cardiovascular diseases [2], diabetes [3], cancer, and obesity [1], all of which are known risk factors for severe COVID-19 [13]. Recent research has also demonstrated a correlation between the COVID-19 pandemic's confinement on physical activity and worsening mental health, with higher levels of stress and anxiety [6]. Moreover, according to the results of the study [14], physical inactivity is associated with a higher risk for severe COVID-19 outcomes.

The United States Physical Activity Guidelines recommend that all adults should engage in at least 150-300 minutes per week of moderate-intensity exercise, if they are able [15]. This is true even for patients with chronic health conditions. In addition, new evidence suggests that regular exercise may reduce the risk of acute respiratory distress syndrome, which is a leading cause of death in COVID-19-afflicted patients [16]. This is mostly due to an increase in the production of extracellular superoxide dismutase during periods of exercise [17]. 


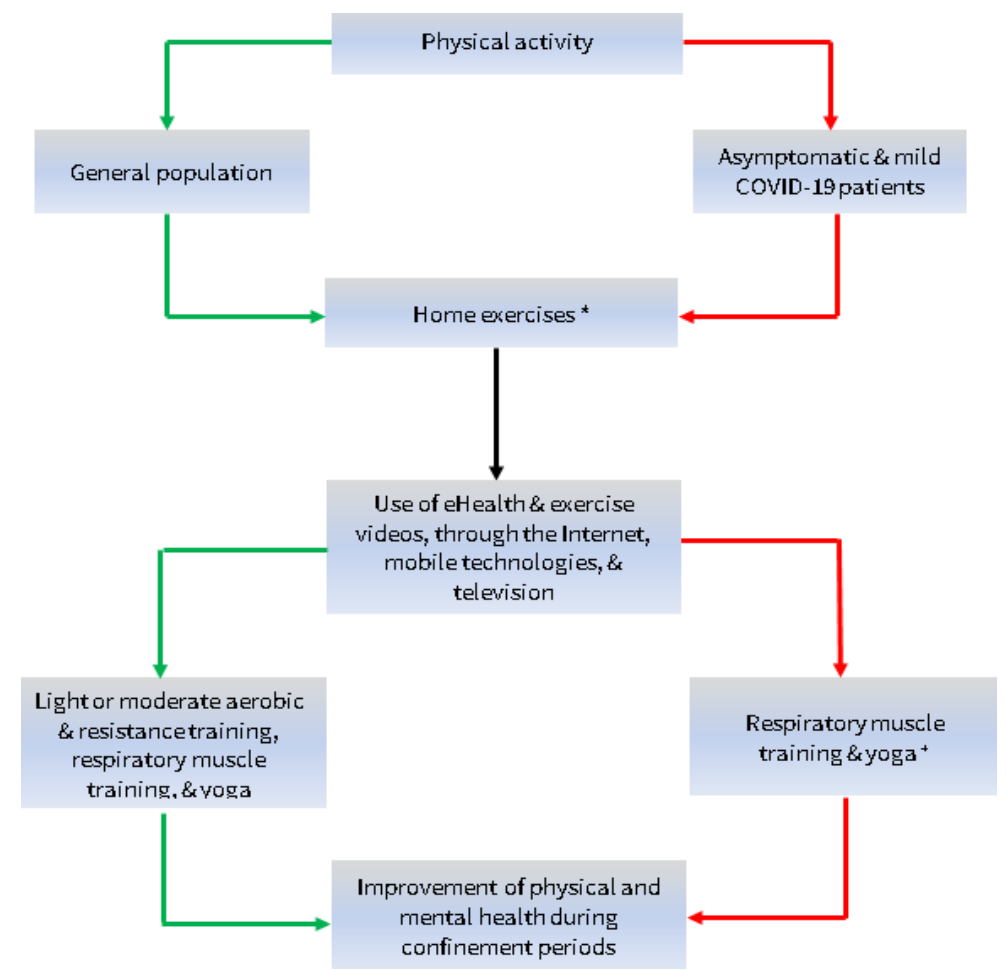

Figure 1. Recommendations for physical activity in healthy people, asymptomatic, and mild COVID-19 patients during periods of confinement due to COVID-19 (Adapted from [4, 12])

\section{RECOMMENDATIONS FOR PHYSICAL EXERCISES DURING THE PANDEMIC}

Given the well-known benefits of physical activity for general health promotion and disease prevention $[3,4,6,12]$, the practice of home exercise should be indicated during the current COVID-19 pandemic for the general population; both asymptomatic people, and those with mild COVID-19 symptoms. In this regard, a home workout program should include aerobic exercise (3-5 times a week, depending on the intensity), strength training (2-3 times a week), flexibilitystretching (2-3 times a week), and balance exercises (2-3 times a week). It is recommended that the general public should perform exercises that allow for the whole body to be trained simultaneously [18]. Figure 1 illustrates the recommendations for physical exercises in these groups. In Figure 1, red arrows mean applicable to asymptomatic and mild COVID-19 patients, green arrows mean applicable to general population, and black arrow means applicable to both groups. Also * means that these should be performed only by people with no previous contraindications to practice physical activities while + means that these should be shorter sessions than for people without COVID-19.

The continuation of physical activity at home is understood to maintain the proper functioning of the immune system [4], which should in turn contribute to the prevention of systemic infection (including SARS-CoV-2 infection). This also contributes to a reduction in the likelehood of disease progression in asymptomatic and mild COVID-19 patients, thus aiding their recovery.

In this sense, it is also worth mentioning the need to implement occupational physical activity for healthcare professionals treating COVID-19 patients. The intention of such schemes would be to contribute to improving and maintaining the health of healthcare professionals, which may therefore result in less physically burnout during the care of COVID-19 patients.

A further important aspect is that physical activity intensity corresponds to the metabolic equivalent of task. Although the metabolic equivalent of a task can be accumulated through activities of daily living, it is essential in the current environment that people expand the variety for home exercises they perform, due to the confinement restrictions restricting our usual daily physical activities. This will also help in achieving satisfactory levels of mental health during the pandemic. Moreover, positive habits of physical activity practice acquired during the confinement period are important to maintain in the future, beyond the pandemic [16]

On the other hand, it should be made clear that physical activities outdoors, including playing sports or exercising at the gym, should only be carried out in accordance with the recommendations of local health authorities and whilst respecting local and current rules regarding social distancing and the use of personal protective equipment (such as masks). For asymptomatic patients or those with mild symptoms, these activities should be performed only in the post-COVID-19 period, after cardiac evaluation. This is in light of evidence to suggest that cardiovascular complications related to prior infection could be present in even mild cases of the disease [19].

In addition, there is growing evidence that physical activity may in fact enhance SARS-CoV-2 vaccine immunogenicity [20], and that vaccination is unlikely to impair exercise capacity in normal healthy people [21]. Given these two findings, engaging in physical activity during the pandemic should be considered an even more valuable and timely practice. 


\section{Body Mass and COVID-19}

During COVID-19, the world's population is also more prone to a loss of lean body mass, mainly due to the need for social isolation [22]. Recent study findings demonstrated that both muscle strength and mass can influence the length of hospital stay of COVID-19 patients. This in turn stresses the value of muscle health in prognosis of the disease [23].

It would therefore be important to implement strategies to maintain or increase the lean muscle mass of populations, to maintain the proper functioning of the immune system [24]. The practice of physical activity to gain lean body mass by mild COVID-19 patients may result in a reduction of fatigue and the prevention of severe breathlessness. Moreover, physical exercise for this purpose may also increase the number of $T$ lymphocytes [22], consequently contributing to the prevention of SARS-CoV-2 infection and COVID-19 progression, which may be of great importance for uninfected and asymptomatic patients. The training plan may mainly include low-intensity exercises, since intense exercises lead to decreasing $T$ lymphocytes, resulting in impaired immunity [22]. Therefore, low-intensity exercises for gaining lean muscle mass should be indicated for healthy people, asymptomatic and mild COVID-19 patients, always following professional advice.

\section{Diet in Times of the COVID-19 Pandemic}

Eating a good quality diet, varied and rich in nutrients, can positively affect the body's immune response. The World Health Organization (WHO) has recommended daily consumption of 2 cups of fruit, 2.5 cups of vegetables, $180 \mathrm{~g}$ of grains, and $160 \mathrm{~g}$ of meat and beans. In addition to proper and adequate nutrition, it is necessary to keep the body hydrated via 8-10 cup of water a day [25]. The adoption of a balanced diet may be of great importance to enhance the above-discussed beneficial effects of physical exercises in the prevention of severe COVID-19 infection. Although much has been studied and discussed in the literature, the evidence surrounding dietary supplementation practices for COVID-19 prevention and/or treatment does not suggest any direct benefits. The only clear evidence is that hypovitaminosis $D$ may be associated with severe COVID-19 infection, which reinforces our recommendations for adopting healthy habits, which should include a proper diet and adequate sun exposure [26].

\section{Sleep During the Pandemic}

Sleep quality is another factor related to functioning of the immune system. In [5], the authors found that sleep quality may be affected during the COVID-19 confinement due to circadian cycle changes and psychological disruption, causing damage to the immune response. This is therefore related to greater susceptibility to SARS-CoV-2 infection, worsening mental health and consequently worsening quality of life. In addition, these changes may predispose patients to the development of other risk factors for severe COVID-19 infection, including obesity, cancer, metabolic syndromes, and ischemic heart disease [27]. The National Sleep Foundation recommends that adults obtain 7-9 hours of sleep a day [28]. It is important to convey this goal to patients, the main objective being to contribute to the better functioning of the immune system during the pandemic.
Effects of Telecommunication, Tele-Education, and Media on Physical Health

In [29], the authors found that several digital platforms have been succesfully used as alternative means for the population to maintain their physical activity at home during periods of pandemic confinement. Among them include: YouTube, Instagram, Facebook, Centr, and MyFitnessPal, and online classes through platforms like Zoom, TeamBuildr, Xbox Kinect, Zwift, FullGaz, and Rouvy. Such platforms played a key role during the pandemic to help the population maintain their physical activity routine in the face of restrictions in attending public spaces [29]. In this context, smart technology has also been proven to be an important adjunct to monitor and promote healthy lifestyles during periods of confinement [30].

If excessive exposure to technologies predisposes to negative consequences during the pandemic [31], their conscious use could be quite beneficial for maintaining the health of the population. In this sense, the effective implementation of telehealth services is a useful tool for physical and mental well-being, especially for patients with chronic conditions [32].

\section{Mental Health Versus Physical Activity}

In a pandemic setting, some groups are more vulnerable to psychological effects, including people who contract the disease, those with comorbidities, and people with preexisting psychiatric or substance use problems [33]. In a recent study [34] involving patients with rheumatoid arthritis, the authors found an association between light physical activity and reduced mental fatigue and better vitality in non-self-isolating people, as well as between walking and less physical fatigue in self-isolating people. Moreover, the correlation between lower levels of physical activity and worsening of mental health in the general population should not be disregarded [6].

Based on this, the suggestion for physical activity during the pandemic should include both healthy and chronically ill patients, in order to achieve widespread better standards of mental health and well-being. This, along with psychological support services [35,36], should also make an important impact for healthcare professionals and relatives of critically ill COVID-19 patients, who could be expected to experience significant levels of mental health deterioration [36,37].

\section{Differences Between Age Groups}

The results of the study [38] show significant differences between age group and prior levels of physical activity during the COVID-19 pandemic. More specifically the findings by Tornaghi et al. demonstrate that the pandemic containment measures may have a negative impact on physical activity levels of the already inactive or moderately active young population [39]. In light of this, governments' response needs to be sensitive to these individual differences and the governments must react accordingly. Therefore, while it is important to encourage physical activity for all age groups, special attention should be paid to younger age groups.

\section{FINAL CONSIDERATION}

The promotion of global initiatives aimed at encouraging regular physical activity coupled with a healthy balanced diet and high uptake of mass vaccination programs, are essential to reduce the global burden of COVID-19 and improve the quality 
of life of our populations [2]. From a local perspective, healthcare professionals should counsel their patients towards appreciating the importance of undertaking regular home exercise, consuming a balanced diet, maintaining adequate amounts of sleep, as well as taking the COVID-19 vaccine when offered.

Author contributions: All authors have sufficiently contributed to the study, and agreed with the results and conclusions.

Funding: No funding source is reported for this study.

Declaration of interest: No conflict of interest is declared by authors.

\section{REFERENCES}

1. Botero JP, Farah BQ, Correia MA, et al. Impact of the COVID19 pandemic stay at home order and social isolation on physical activity levels and sedentary behavior in Brazilian adults. Einstein (São Paulo). 2021;19:eAE6156. https://doi.org/10.31744/einstein_journal/2021AE6156 PMid:33681886 PMCid:PMC7909004

2. Mattioli AV, Sciomer S, Cocchi C, Maffei S, Gallina S. Quarantine during COVID-19 outbreak: Changes in diet and physical activity increase the risk of cardiovascular disease. Nutr Metab Cardiovasc Dis. 2020;30(9):1409-17. https://doi.org/10.1016/j.numecd.2020.05.020 PMid: 32571612 PMCid:PMC7260516

3. Marçal IR, Fernandes B, Viana AA, Ciolac EG. The urgent need for recommending physical activity for the management of diabetes during and beyond COVID-19 outbreak. Front Endocrinol (Lausanne). 2020;11:584642. https://doi.org/10.3389/fendo.2020.584642 PMid: 33250859 PMCid:PMC7673403

4. Chen P, Mao L, Nassis GP, Harmer P, Ainsworth BE, Li F. Coronavirus disease (COVID-19): The need to maintain regular physical activity while taking precautions. J Sport Health Sci. 2020;9(2):103-4. https://doi.org/10.1016/ j.jshs.2020.02.001 PMid:32099716 PMCid:PMC7031771

5. Silva ESME, Ono BHVS, Souza JC. Sleep and immunity in times of COVID-19. Rev Assoc Med Bras (1992). 2020;66(Suppl 2):143-7. https://doi.org/10.1590/1806-9282 .66.S2.143 PMid:32965373

6. Duncan GE, Avery AR, Seto E, Tsang S. Perceived change in physical activity levels and mental health during COVID-19: Findings among adult twin pairs. PLoS One. 2020;15(8):e0237695. https://doi.org/10.1371/journal.pone .0237695 PMid:32790745 PMCid:PMC7425865

7. Johns Hopkins Coronavirus Resource Center. World Map. Baltimore. 2021. Available at: https://coronavirus.jhu.edu/ map.html (Accessed 14 May 2021)

8. McPhillips D. Delta variant's trajectory in UK and Israel provides hope for US--if we can keep vaccinating. Atlanta: CNN, 2021 Jul 12. Available at: https://edition.cnn.com/ 2021/07/09/health/delta-variant-trends-israel-uk/index. html (Accessed: 21 July 2021).

9. Soiza RL, Scicluna C, Thomson EC. Efficacy and safety of COVID-19 vaccines in older people. Age Ageing. 2021;50(2):279-83. https://doi.org/10.1093/ageing/afaa274 PMid:33320183 PMCid:PMC7799251

10. Nhamo G, Chikodzi D, Kunene HP, Mashula N. COVID-19 vaccines and treatments nationalism: Challenges for lowincome countries and the attainment of the SDGs. Glob Public Health. 2021;16(3):319-39. https://doi.org/10.1080/ 17441692.2020.1860249 PMid:33317389
11. Kamal M, Abo Omirah M, Hussein A, Saeed H. Assessment and characterisation of post-COVID-19 manifestations. Int J Clin Pract. 2021;75(3):e13746. https://doi.org/10.1111/ ijcp.13746 PMid:32991035 PMCid:PMC7536922

12. Khoramipour K, Basereh A, Hekmatikar AA, Castell L, Ruhee RT, Suzuki K. Physical activity and nutrition guidelines to help with the fight against COVID-19. J Sports Sci. 2021;39(1):101-7. https://doi.org/10.1080/02640414.2020. 1807089 PMid:32842905

13. Gao YD, Ding M, Dong $X$, et al. Risk factors for severe and critically ill COVID-19 patients: A review. Allergy. 2021;76(2):428-55. https://doi.org/10.1111/all.14657 PMid: 33185910

14. Sallis R, Young DR, Tartof SY, et al. Physical inactivity is associated with a higher risk for severe COVID-19 outcomes: A study in 48440 adult patients. Br J Sports Med. 2021:bjsports-2021-104080. https://doi.org/10.1136/ bjsports-2021-104080 PMid:33849909 PMCid:PMC8050880

15. Yang YJ. An overview of current physical activity recommendations in primary care. Korean J Fam Med. 2019;40(3):135-42. https://doi.org/10.4082/kjfm.19.0038 PMid:31122003 PMCid:PMC6536904

16. Nyenhuis SM, Greiwe J, Zeiger JS, Nanda A, Cooke A. Exercise and fitness in the age of social distancing during the COVID-19 pandemic. J Allergy Clin Immunol Pract. 2020;8(7):2152-5. https://doi.org/10.1016/j.jaip.2020.04. 039 PMid:32360185 PMCid:PMC7187829

17. Yan Z, Spaulding HR. Extracellular superoxide dismutase, a molecular transducer of health benefits of exercise. Redox Biol. 2020;32:101508. https://doi.org/10.1016/j.redox.2020. 101508 PMid:32220789 PMCid:PMC7109453

18. Polero P, Rebollo-Seco C, Adsuar JC, et al. Physical activity recommendations during COVID-19: Narrative review. Int J Environ Res Public Health. 2020;18(1):65. https://doi.org/ 10.3390/ijerph18010065 PMid:33374109 PMCid: PMC7796360

19. Bansal M. Cardiovascular disease and COVID-19. Diabetes Metab Syndr. 2020;14(3):247-50. https://doi.org/10.1016/j. dsx.2020.03.013 PMid:32247212 PMCid:PMC7102662

20. Gualano B, Lemes IR, Silva RP, et al. Association between physical activity and immunogenicity of an inactivated virus vaccine against SARS-CoV-2 in patients with autoimmune rheumatic diseases. Brain Behav Immun. 2021;101:49-56. https://doi.org/10.1016/j.bbi.2021.12.016 PMid:34954325 PMCid:PMC8697420

21. Batatinha H, Baker FL, Smith KA, et al. Recent COVID-19 vaccination has minimal effects on the physiological responses to graded exercise in physically active healthy people. J Appl Physiol (1985). 2022;132(2):275-82. https:// doi.org/10.1152/japplphysiol.00629.2021 PMid:34882029

22. Codella R, Chirico A, Lucidi F, Ferrulli A, La Torre A, Luzi L. The immune-modulatory effects of exercise should be favorably harnessed against COVID-19. J Endocrinol Invest. 2021;44(5):1119-22. https://doi.org/10.1007/s40618-02001403-5 PMid:32885340 PMCid:PMC7471548

23. Gil S, Jacob Filho W, Shinjo SK, et al. Muscle strength and muscle mass as predictors of hospital length of stay in patients with moderate to severe COVID-19: a prospective observational study. J Cachexia Sarcopenia Muscle. 2021;12(6):1871-8. https://doi.org/10.1002/jcsm.12789 PMid:34523262 PMCid:PMC8661522 
24. Laddu DR, Lavie CJ, Phillips SA, Arena R. Physical activity for immunity protection: Inoculating populations with healthy living medicine in preparation for the next pandemic. Prog Cardiovasc Dis. 2021;64:102-4. https://doi.org/10.1016/j.pcad.2020.04.006 PMid:32278694 PMCid:PMC7195025

25. World Health Organization. Nutrition advice for adults during the COVID-19 outbreak. 2020. Available at: http://www.emro.who.int/nutrition/nutrition-infocus/ nutrition-advice-for-adults-during-the-covid-19outbreak.html (Accessed: 21 July 2021).

26. Giacalone A, Marin L, Febbi M, Tovani-Palone MR. Current evidence on vitamin $C, D$, and zinc supplementation for COVID-19 prevention and/or treatment. Electron J Gen Med. 2021;18(5):em311. https://doi.org/10.29333/ejgm/ 11099

27. Ashbrook LH, Krystal AD, Fu YH, Ptáček LJ. Genetics of the human circadian clock and sleep homeostat. Neuropsychopharmacology. 2020;45(1):45-54. https://doi.org/10.1038/s41386-019-0476-7 PMid:31400754 PMCid:PMC6879540

28. Hirshkowitz M, Whiton K, Albert SM, et al. National Sleep Foundation's sleep time duration recommendations: Methodology and results summary. Sleep Health. 2015;1(1):40-3. https://doi.org/10.1016/j.sleh.2014.12.010 PMid:29073412

29. Parker K, Uddin R, Ridgers ND, et al. The use of digital platforms for adults' and adolescents' physical activity during the COVID-19 pandemic (our life at home): Survey study. J Med Internet Res. 2021;23(2):e23389. https://doi.org/10.2196/23389 PMid:33481759 PMCid: PMC7857525

30. Buoite Stella A, AjČević M, Furlanis G, et al. Smart technology for physical activity and health assessment during COVID-19 lockdown. J Sports Med Phys Fitness. 2021;61(3):452-60. https://doi.org/10.23736/S00224707.20.11373-2 PMid:33092330

31. Desideri LF, Tovani-Palone MR. COVID-19 and the increased risk of myopia and digital eye strain. Einstein (São Paulo). 2021;19:eCE6491. https://doi.org/10.31744/einstein_ journal/2021CE6491 PMid:34037086 PMCid:PMC8121374
32. Giacalone A, Marin L, Febbi M, Franchi T, Tovani-Palone MR. eHealth, telehealth, and telemedicine in the management of the COVID-19 pandemic and beyond: Lessons learned and future perspectives. World J Clin Cases. 2022. In press.

33. Pfefferbaum B, North CS. Mental health and the COVID-19 pandemic. N Engl J Med. 2020;383(6):510-2. https://doi.org/10.1056/NEJMp2008017 PMid:32283003

34. Brady SM, Fenton SAM, Metsios GS, et al. Different types of physical activity are positively associated with indicators of mental health and psychological wellbeing in rheumatoid arthritis during COVID-19. Rheumatol Int. 2021;41(2):33544. https://doi.org/10.1007/s00296-020-04751-w PMid: 33258004 PMCid:PMC7703721

35. Tovani-Palone MR, Ali S. Psychological support to relatives of critically ill patients with COVID-19. Einstein (São Paulo). 2020;18:eCE6032. https://doi.org/10.31744/einstein_ journal/2020CE6032

36. Franchi T, Shah PA, Tovani-Palone MR. Mental health during a pandemic: Additional action is required. Acta Med Port. 2022;35(1):71-2. https://doi.org/10.20344/amp.17407

37. Quispe-Sancho A, Chambi-Macedo KL, Laurel-Vargas V, et al. Depression, anxiety, and stress in health professionals working during the COVID-19 pandemic in Peru: An analytical cross-sectional study. Electron J Gen Med. 2021;18(6):em319. https://doi.org/10.29333/ejgm/11210

38. McCarthy H, Potts HWW, Fisher A. Physical activity behavior before, during, and after COVID-19 restrictions: Longitudinal smartphone-tracking study of adults in the United Kingdom. J Med Internet Res. 2021;23(2):e23701. https://doi.org/10.2196/23701 PMid:33347421 PMCid: PMC7861037

39. Tornaghi M, Lovecchio N, Vandoni M, Chirico A, Codella R. Physical activity levels across COVID-19 outbreak in youngsters of Northwestern Lombardy. J Sports Med Phys Fitness. 2021;61(7):971-6. https://doi.org/10.23736/S00224707.20.11600-1 PMid:33269881 